\title{
Activation of Group II Metabotropic Glutamate Receptors Attenuates Both Stress and Cue-Induced Ethanol-Seeking and Modulates c-fos Expression in the Hippocampus and Amygdala
}

\author{
Yu Zhao, ${ }^{\star}$ Christopher V. Dayas, ${ }^{\star}$ Harinder Aujla, Marco A. S. Baptista, Rémi Martin-Fardon, and Friedbert Weiss \\ Molecular and Integrative Neurosciences Department, The Scripps Research Institute, La Jolla, California 92037
}

\begin{abstract}
Major precipitating factors for relapse to drug use are stress and exposure to drug-related environmental stimuli. Group II ( $\mathrm{mGlu}_{2 / 3}$ ) metabotropic glutamate receptors (mGluRs) are densely expressed within circuitries mediating the motivating effects of stress and drug cues and, therefore, may participate in regulating drug-seeking linked to both of these risk factors. Thus, we tested the hypothesis that pharmacological activation of group II mGluRs modifies both stress- and cue-induced ethanol-seeking, using reinstatement models of relapse. In parallel, brain c-fos expression was examined to identify neural substrates for the behavioral effects of group II mGluR activation. The selective $\mathrm{mGlu}_{2 / 3}$ agonist LY379268 (1R,4R,5S,6R-2-oxa-4-aminobicyclo[3.1.0] hexane-4,6-dicarboxylate) (0.3, 1.0, and $3.0 \mathrm{mg} / \mathrm{kg}$, s.c.) dose dependently blocked the recovery of extinguished ethanol-seeking induced by either footshock stress or ethanolassociated discriminative stimuli. These effects were accompanied by modulation of c-fos expression in the hippocampus, central nucleus of the amygdala, bed nucleus of the stria terminalis, and medial parvocellular paraventricular nucleus of the hypothalamus. The results implicate group II mGluRs as a shared neuropharmacological substrate for ethanol-seeking elicited by both drug cues and stress and identify group II mGluRs as promising treatment targets for relapse prevention.
\end{abstract}

Key words: addiction; anxiolytic; glutamate; reinstatement; relapse; alcohol

\section{Introduction}

The development of selective ligands for metabotropic glutamate receptors (mGluRs) has provided novel opportunities for investigating the role of glutamate neurotransmission in psychiatric conditions linked to glutamatergic hyperexcitability, including drug addiction and anxiety disorders. Of particular interest in this respect are group II mGluRs $\left(\mathrm{mGlu}_{2 / 3}\right)$ because of their abundance in brain regions mediating drug reward and incentive motivation (Ohishi et al., 1993a,b), as well as circuitries regulating anxiety and behavioral responses to stress (Kenny and Markou, 2004; Swanson et al., 2005). Group II mGluRs negatively modulate excitatory glutamate transmission at the presynaptic, perisynaptic, and postsynaptic levels (Schoepp, 2001). Such actions in brain reward and stress systems, including the nucleus

Received Nov. 20, 2005; revised Aug. 3, 2006; accepted Aug. 24, 2006.

This work was supported by National Institutes of Health/National Institute on Alcohol Abuse and Alcoholism Grants AA10531 and AA06420 (F.W.).C.V.D. was supported by a C. J. Martin Fellowship (National Health and Medical Research Council, Australia). We thank Dr. Darryle Schoepp (Lilly Research Laboratories, Indianapolis, IN) for generously providing LY379268, Mike Arends for editorial assistance, Kris Trulock and Charles Peto, (The Salk Institute, La Jolla, (A) for providing expertise and facilities for photomicrograph production, as well as Jeffrey Simms and Kristen Santerre for excellent technical assistance. This is publication 17698-NP from The Scripps Research Institute.

*Y.Z. and C.V.D. contributed equally to this work.

Correspondence should be addressed to Dr. Christopher V. Dayas, Molecular and Integrative Neurosciences Department, The Scripps Research Institute (SP30-2120), 10550 North Torrey Pines Road, La Jolla, CA 92037. E-mail: cvdayas@scripps.edu.

DOI:10.1523/JNEUROSCI.2384-06.2006

Copyright (C) 2006 Society for Neuroscience $\quad 0270-6474 / 06 / 269967-08 \$ 15.00 / 0$ accumbens, amygdala, dorsal hippocampus (HIPPO), and ventral tegmental area (VTA) (Kenny and Markou, 2004; Swanson et al., 2005), are likely to be important for the addictive actions of drugs of abuse as well as addiction-relevant actions of stress. Indeed, $\mathrm{mGlu}_{2 / 3}$ agonists attenuate some forms of drug-seeking behavior (Baptista et al., 2004; Bossert et al., 2004) and modify several neurobehavioral consequences of acute and chronic psychostimulant or opiate administration (Kenny and Markou, 2004). Additionally, these agents exert anxiolytic-like effects in animals and appear effective in the treatment of anxiety disorders (Swanson et al., 2005).

A significant obstacle for the successful treatment of drug addiction is persistent vulnerability to relapse. Major precipitating factors for the resumption of drug use are stress and exposure to drug-related environmental stimuli (O'Brien et al., 1998; Sinha et al., 2000; See, 2002; Weiss, 2005). Considering the "strategic" distribution of group II mGluRs within brain circuitries that control the motivating effects of stress and drug-related stimuli, these receptors may have a pivotal role in drug-seeking behavior linked to these risk factors and offer a potential treatment target for relapse prevention. This hypothesis is tentatively supported by findings that an $\mathrm{mGlu}_{2 / 3}$ agonist prevents cocaine- and heroinseeking behavior induced by drug-related contextual stimuli in reinstatement models of relapse (Baptista et al., 2004; Bossert et al., 2004). The purpose of this study was (1) to determine whether group II mGluR activation by a selective $\mathrm{mGlu}_{2 / 3}$ agonist 
[LY379268 $(1 R, 4 R, 5 S, 6 R$-2-oxa-4-aminobicyclo[3.1.0]hexane4,6-dicarboxylate)] attenuates not only cue- but also stressinduced reinstatement of drug-seeking, using ethanol as a representative substance of abuse, and (2) to identify potential neural substrates through which group II mGluR activation modifies the reinstatement of ethanol-seeking by using c-fos neural mapping.

\section{Materials and Methods}

Animals. Male Wistar rats (Charles River, Raleigh, NC) weighing 180$200 \mathrm{~g}$ were housed three per cage on a reversed $12 \mathrm{~h}$ light/dark cycle with food and water available ad libitum. All procedures were conducted in accordance with the National Institutes of Health Guide for the Care and Use of Laboratory Animals and were approved by the Institutional Animal Care and Use Committee of The Scripps Research Institute.

Drugs. The $\mathrm{mGlu}_{2 / 3}$ receptor agonist LY379268 (Lilly Research Laboratories, Indianapolis, IN) was dissolved in sterile water at volumes of 0.3 , 1.0 , and $3.0 \mathrm{mg} / \mathrm{ml}$. LY379268 [or vehicle (VEH)] was administered subcutaneously $30 \mathrm{~min}$ before behavioral tests.

Ethanol self-administration training. Rats were trained to orally selfadminister ethanol in 30 min daily sessions inside sound-attenuated operant conditioning chambers (Med Associates, St. Albans, VT), using a sweet solution fading procedure. Briefly, responses at an active lever were initially reinforced by $0.1 \mathrm{ml}$ of saccharin $(0.2 \% \mathrm{w} / \mathrm{v})$ on a fixed ratio 1 (FR 1) schedule. After acquisition, ethanol $(5 \% \mathrm{w} / \mathrm{v})$ was added to the saccharin solution. Ethanol concentrations then were gradually increased to $10 \%(\mathrm{w} / \mathrm{v})$ while saccharin was slowly eliminated. A second inactive lever was then introduced at which responses were recorded but had no programmed consequences.

Footshock reinstatement procedure. Once stable ethanol selfadministration was obtained, daily $30 \mathrm{~min}$ sessions continued for 4 weeks. Ethanol-reinforced responding was then extinguished in daily 30 min sessions that continued until a criterion (average of less than or equal to six lever presses over $3 \mathrm{~d}$ ) was reached by a given animal, which required, on average, $14 \mathrm{~d}$. Reinstatement tests began $1 \mathrm{~d}$ after the last extinction session. Thirty minutes after LY379268 (0.3, 1.0, and $3.0 \mathrm{mg} /$ $\mathrm{kg}$, s.c.) administration, rats were exposed to $10 \mathrm{~min}$ of variable intermittent footshock $(0.5 \mathrm{~mA}$; $0.5 \mathrm{~s}$ duration; mean intershock interval, $40 \mathrm{~s}$; range, 10-70 s). After footshock, levers were extended and $60 \mathrm{~min}$ reinstatement tests began. Because behavioral responses (including drugseeking behavior) to footshock are often highly variable, a large sample size $(n=19-20$ per group) was selected to ensure sufficient statistical power.

Conditioned reinstatement procedure. After acquisition of ethanol selfadministration in the training phase, rats were trained to associate compound discriminative stimuli with the availability of ethanol versus nonreward. Ethanol was available in the presence of an " $\mathrm{S}$ " " consisting of an olfactory cue (banana extract; McCormick \& Co, Hunt Valley, MD) paired with a constant white noise $(70 \mathrm{~dB})$. Nonreward was signaled by an " $\mathrm{S}$ " " consisting of anise extract paired with a constant beeping tone ( 7 $\mathrm{kHz}, 70 \mathrm{~dB}$ ). Olfactory stimuli were generated by depositing six drops (100 $\mu \mathrm{l} / \mathrm{drop}$ ) of distinct food flavor extracts into the bedding of the operant conditioning chamber $1 \mathrm{~min}$ before extension of the lever. The respective stimuli remained present throughout the $30 \mathrm{~min}$ sessions. The bedding was changed and trays were cleaned between sessions. Conditioning with the $\mathrm{S}^{+}$and $\mathrm{S}^{-}$was conducted in random sequence across days until rats completed 20 ethanol and 20 nonreward sessions. Rats then were subjected to daily 30 min extinction sessions, as above, during which both ethanol and discriminative stimuli were withheld until the criterion was reached. Responses at the previously active lever activated the syringe pump motor but had no other scheduled consequences.

One day after the final extinction session, 30 min reinstatement tests began under extinction conditions, except that the discriminative stimuli were reintroduced and remained present throughout the sessions. Rats were tested first in the presence of the $\mathrm{S}^{-}$(after vehicle administration). After an intervening day, rats were tested in the presence of the $\mathrm{S}^{+}$after LY379268 (0.3, 1.0, and $3.0 \mathrm{mg} / \mathrm{kg}$, s.c.), administered $30 \mathrm{~min}$ before the beginning of the session. Drug tests were conducted in separate groups of rats for each dose.
Food-reinforced responding. To control for possible nonspecific actions of LY379268, the effects of the $\mathrm{mGlu}_{2 / 3}$ agonist on food-reinforced responding were tested in a group of rats maintained on a food-restricted $\operatorname{diet}(15 \mathrm{~g}$ rat chow per day). These animals were trained to respond for 45 mg food pellet reinforcers (Research Diets, New Brunswick, NJ) on an FR 1 schedule in daily $30 \mathrm{~min}$ sessions. After acquisition, daily sessions continued until rats displayed stable food responding ( $\pm 10 \%$ over three consecutive sessions). On the test day, rats were treated with LY379268 $(0.3,1.0$, and $3.0 \mathrm{mg} / \mathrm{kg}$, s.c.) using separate groups for each dose $(n=6$ per group).

$c$-fos neural mapping. To identify potential neural substrates through which LY379268 exerts its inhibitory effects on conditioned and stressinduced reinstatement, c-fos neural mapping was used with the following experimental strategy. Initially, the pharmacological effects of LY379268 on c-fos expression in the absence of behavioral manipulations were determined in two groups of ethanol-naive rats ( $n=6$ per group) injected with either vehicle or LY379268 (3 mg/kg, s.c.). Next, the effects of ethanol $\mathrm{S}^{+}$exposure $(n=9)$ and footshock $(n=8)$ on c-fos expression in VEH-treated animals were compared with expression levels in rats with the same experimental history and degree of ethanol exposure as the experimental animals but without being subjected to reinstatement tests. For this purpose, brain tissue from a group of rats $(n=5)$ that had reached the extinction criterion and treated with VEH 30 min before the final extinction session was used. Last, the degree to which the $\mathrm{mGlu}_{2 / 3}$ agonist alters specific c-fos expression changes induced by the ethanol $\mathrm{S}^{+}$ $(n=8)$ and footshock $(n=8)$ was established in rats after completion of reinstatement tests in the $3.0 \mathrm{mg} / \mathrm{kg}$ LY379268 groups compared with c-fos expression in the VEH reinstatement conditions. In the case of footshock, animals for c-fos expression analysis were randomly selected from all rats assigned to stress-reinstatement tests.

Fos-protein immunohistochemistry. At 120 min after LY379268 or vehicle administration (i.e., 90 min after reinstatement or extinction sessions), rats were deeply anesthetized and perfused with $0.9 \%$ saline, followed by $4 \%$ paraformaldehyde, $\mathrm{pH} 9.5,4^{\circ} \mathrm{C}$. After cryoprotection, serial $40 \mu \mathrm{m}$ coronal forebrain sections were cut on a freezing microtome. c-fos expression was gauged by processing sections for Fos-protein immunohistochemistry as described by Dayas et al. (1999). Briefly, sections were incubated in Fos primary antisera (1:5000, rabbit polyclonal, Santa Cruz Biotechnology, Santa Cruz, CA). After Fos-immunolabeling, sections encompassing the VTA were also processed for immunohistochemical detection of the catecholaminergic marker tyrosine hydroxylase (TH) (anti-TH, 1:15,000, mouse-monoclonal; DiaSorin, Stillwater, MN) for identification of A10 dopaminergic neurons. Sections were incubated in appropriate secondary antisera (2 h; Jackson ImmunoResearch, West Grove, PA), followed by avidin-biotin-horseradish peroxidase complex solution (2 h; Vector Elite kit; Vector Laboratories, Burlingame, CA). Nickel diaminobenzidine (DAB) was used to visualize horseradish peroxidase activity in the case of Fos, DAB alone, for TH.

Counts of Fos-positive cells were made within the following: the medial prefrontal cortex (mPFC), incorporating the prelimbic cortex and the $\mathrm{Cg} 1$ and $\mathrm{Cg} 2$ divisions of the anterior cingulate cortex $(2.2-2.86 \mathrm{~mm}$ rostral to bregma); nucleus accumbens core (NACc) and shell (NACsh) (1.76 and $1.6 \mathrm{~mm}$ rostral to bregma); dorsolateral bed nucleus of the stria terminalis (BST-LD) (0.08 to $-0.4 \mathrm{~mm}$ relative to bregma); lateral (CeA-L) and medial (CeA-M) divisions of the central amygdala and basolateral amygdala (BLA) $(-2.12$ to $-2.92 \mathrm{~mm}$ relative to bregma); $\mathrm{HIPPO}$, including the CA1, CA3, and dentate gyrus (DG) divisions $(-2.80$ to $-3.12 \mathrm{~mm}$ relative to bregma); and the medial parvocellular division of the paraventricular nucleus of the hypothalamus (mpPVN) $(-1.48$ to $-2.12 \mathrm{~mm}$ relative to bregma). For the VTA, Fos-positive TH-labeled cells were counted over three sections $(-5.20$ to $-5.60 \mathrm{~mm}$ relative to bregma).

Statistical analysis. Effects of LY379268 on stress- and cue-induced reinstatement were analyzed by $4 \times 2$ mixed-factorial ANOVA with drug dose as a between-subjects factor and experimental phase (extinction vs reinstatement) as a within-subjects factor. Significant interactions were followed by Fisher's PLSD post hoc tests to evaluate differences between extinction and reinstatement responses as well as among drug doses. Effects of LY379268 on food-maintained responding were analyzed by 

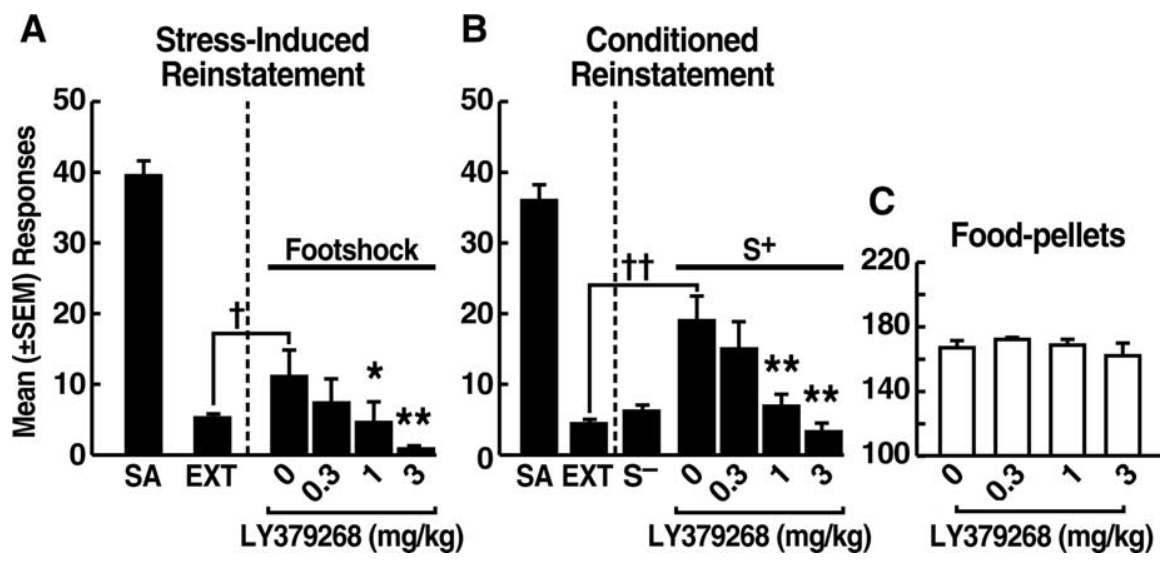

Figure 1. Effects of $L Y 379268$ on mean \pm SEM lever responses in the following: $\boldsymbol{A}$, stress-induced reinstatement tests ( 0 $\mathrm{mg} / \mathrm{kg}, n=19 ; 0.3-3 \mathrm{mg} / \mathrm{kg}, n=20) ; \boldsymbol{B}$, conditioned reinstatement tests $\left(\mathrm{S}^{+}\right)(0 \mathrm{mg} / \mathrm{kg}, n=9 ; 0.3-1 \mathrm{mg} / \mathrm{kg}, n=7 ; 3 \mathrm{mg} / \mathrm{kg}$, $n=8)$; and $C$, tests of food-reinforced responding $(n=6)$. ${ }^{\dagger} p<0.05,{ }^{{ }^{\dagger}} p<0.01$, different from extinction. ${ }^{*} p<0.05,{ }^{* *} p<$ 0.01, different from $0 \mathrm{mg} / \mathrm{kg}$ LY379268. SA, Self-administration; EXT, Extinction.

one-way ANOVA, followed by Fisher's PLSD post hoc tests to verify differences between vehicle and drug effects. Fos-immunoreactivity data were analyzed by Mann-Whitney $U$ nonparametric tests. (This nonparametric statistic was used because of violations of normality in raw Fospositive cell counts.) Separate tests were conducted for each brain region to evaluate the effect of LY379268 versus vehicle treatment and to determine differences in counts between the extinction and reinstatement conditions in each brain region. Fos data are expressed as mean \pm SEM of the total number of Fos-positive cells.

\section{Results}

Effects of LY379268 on stress-induced reinstatement

The mean \pm SEM number of ethanol-reinforced responses across the final three self-administration sessions was $40.8 \pm 3.0$ (Fig. 1A). Rats reached the extinction criterion within 2 weeks. Footshock elicited significant $(p<0.05)$ recovery of responding in vehicle-treated rats (mean \pm SEM, $11 \pm 3.7$ ) (Fig. 1A). LY379268 dose dependently attenuated footshock-induced reinstatement with significant effects at the $1.0(p<0.05)$ and 3.0 $(p<0.01) \mathrm{mg} / \mathrm{kg}$ doses (Fisher's PLSD tests after dose $\times$ experimental phase interaction, $\left.F_{(3,75)}=2.729 ; p<0.05\right)$ (Fig. 1A). Several rats showed lever generalization after footshock and responded at both the active and inactive levers. Inactive lever responses, however, did not differ statistically from extinction responses in any group.

\section{Effects of LY379268 on conditioned reinstatement}

The mean \pm SEM number of ethanol-reinforced responses across the final three sessions of the conditioning phase was $36.0 \pm 2.0$. Rats reached the extinction criterion within 2 weeks. Presentation of the ethanol $\mathrm{S}^{+}$elicited significant $(p<0.01)$ recovery of responding in vehicle-treated rats (mean \pm SEM responses, $19.0 \pm 3.5$ ) (Fig. 1 B). LY379268 dose dependently decreased the response-reinstating actions of the $\mathrm{S}^{+}$with significant effects at the $1.0(p<0.01)$ and $3.0(p<0.01) \mathrm{mg} / \mathrm{kg}$ doses (Fisher's PLSD tests after dose $\times$ experimental phase interaction, $F_{(3,27)}=8.122 ; p<0.01$ ) (Fig. $1 B$ ). Responses in the presence of the $\mathrm{S}^{-}$remained at extinction levels. Inactive lever responses were negligible throughout all experimental phases.

\section{Effects of LY379268 on food-reinforced responding}

All rats acquired stable food-reinforced responding after $10 \mathrm{~d}$ (mean \pm SEM responses across the final three sessions, $167.0 \pm$
4.1). LY379268 did not alter foodreinforced behavior at any dose (Fig. 1C).

Effects of stress and ethanol cue exposure on Fos immunoreactivity Compared with extinction controls, footshock significantly increased Fos-positive cell counts within the NACc $(U=0 ; p<$ $0.01)$, NACsh $(U=0 ; p<0.01)$, BLA $(U=$ $0 ; p<0.01)$, VTA A10 cells $(U=0 ; p<$ $0.01)$, CeA-L $(U=1.5 ; p<0.01)$, CeA-M $(U=0 ; p<0.01)$, BST-LD $(U=3 ; p<$ 0.01 ), and mpPVN $(U=0 ; p<0.01)$ (see Fig. $3 B-D, F)$. However, within the mPFC and HIPPO, Fos-immunoreactive cell counts in footshock-exposed rats were not significantly different from those in the extinction group (see Fig. $3 A-E$ ). To confirm that the rats randomly selected for Fos-protein immunohistochemistry (Fos subgroup) were representative of the entire stress reinstatement group, the behavioral data of these animals $(n=8)$ were compared with those of the remaining 11 animals (non-Fos subgroup) by mixed-factorial ANOVA. The two subgroups were statistically indistinguishable in terms of both stress-induced responding at the $0 \mathrm{mg} / \mathrm{kg}$ dose (i.e., vehicle) of LY379268 (group $\times$ experimental phase interaction, $F_{(1,17)}=1.747$; NS) and the attenuation of reinstatement at the $3 \mathrm{mg} / \mathrm{kg}$ LY379268 dose (group $\times$ experimental phase interaction, $F_{(1,18)}=0.699$; NS). Rats in the Fos subgroup showed significant reinstatement versus extinction, as well as significantly reduced reinstatement after $3 \mathrm{mg} / \mathrm{kg}$ LY379268 ( $p<0.05$; Fisher's PLSD tests after dose $\times$ experimental phase interaction, $F_{(1,14)}=6.104 ; p<0.05$ ) (Fig. $2 A$ ).

Rats exposed to the ethanol $\mathrm{S}^{+}$showed significantly increased numbers of Fos-positive cells within the $\operatorname{mPFC}(U=3.0 ; p<$ $0.05)$, NACc $(U=0 ; p<0.01)$, NACsh $(U=0 ; p<0.01)$, BLA $(U=4 ; p<0.05)$, VTA A 10 cells $(U=4 ; p<0.05)$, CA1 $(U=1$; $p<0.01)$, CA3 $(U=3 ; p<0.01)$, DG $(U=0 ; p<0.01)$, and within the CeA-L $(U=4.0 ; p<0.05)$, CeA-M $(U=0 ; p<0.01)$, and BST-LD $(U=0 ; p<0.01)$ compared with counts in the extinction control group (Fig. $3 A-F$ ).

\section{Modification of stress- and cue-induced Fos immunoreactivity by LY379268}

Footshock stress

No differences in Fos-positive cell counts were observed between LY379268 and vehicle-treated rats exposed to footshock within the mPFC, the NACc and NACsh, BLA, and VTA A10 cells (Fig. $3 A-D)$. LY379268 reduced Fos-positive cell counts in the hippocampal CA1 $(U=11 ; p<0.05)$ and CA3 $(U=10 ; p<0.05)$ but not the DG division compared with the stress-exposed vehicle group $(U=13.5 ; p>0.05)$ (Figs. $3 E)$. Compared with vehicle, LY379268 increased Fos-positive neurons in rats subjected to footshock within the CeA-L $(U=11 ; p<0.05)$ and CeA-M $(U=$ 13 ; $p<0.05)$, the BST-LD $(U=7.5 ; p<0.01)$, and $\operatorname{mpPVN}(U=$ $4 ; p<0.01$ ) (Fig. 3F).

Ethanol cue exposure

Within the mPFC, and NACc and NACsh, VTA A10 cells, and the BLA, rats exposed to the ethanol S ${ }^{+}$showed identical levels of Fos immunoreactivity regardless of treatment condition (LY379268 or vehicle) (Fig. $3 A-D$ ). LY379268 significantly reduced Fos- 
A

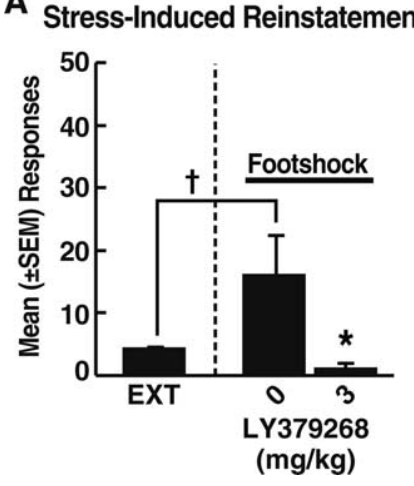

B Conditioned Reinstatement

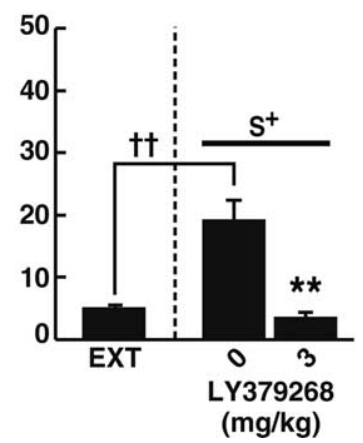

Figure 2. Effects of $L Y 379268(3 \mathrm{mg} / \mathrm{kg})$ or vehicle on mean \pm SEM lever responses in the subgroup of animals used for analysis of $c$-fos expression. $\boldsymbol{A}$, Stress-induced reinstatement $(0$ $\mathrm{mg} / \mathrm{kg}, n=8 ; 3 \mathrm{mg} / \mathrm{kg}, n=8) . \boldsymbol{B}$, Conditioned reinstatement $\left(\mathrm{S}^{+}\right)(0 \mathrm{mg} / \mathrm{kg}, n=9 ; 3 \mathrm{mg} / \mathrm{kg}$, $n=8) .{ }^{+} p<0.05,{ }^{+\dagger} p<0.01$, different from extinction (EXT). ${ }^{*} p<0.05,{ }^{* *} p<0.01$, different from $0 \mathrm{mg} / \mathrm{kg}$ LY379268.

positive cells within the CA1 $(U=11 ; p<0.05)$, CA3 $(U=7$; $p<$ $0.01)$, and DG $(U=12 ; p<0.05)$ of $S^{+}$-exposed rats compared with $\mathrm{S}^{+}$effects in the vehicle group, similar to the effects of the drug on stress-induced Fos-immunoreactivity (Figs. 3E, $4 C-H$ ). Within the CeA-L $(U=3 ; p<0.01)$ and CeA-M $(U=11 ; p<$ $0.05)$, BST-LD $(U=9 ; p<0.05)$, and $\operatorname{mpPVN}(U=5 ; p<0.01)$, Fos-positive cell counts were significantly elevated in rats exposed to the ethanol $\mathrm{S}^{+}$and treated with LY379268 compared with vehicle-treated animals (Figs. $3 F, 4 A, B$ ).

\section{Effects of LY379268 in naive animals}

The effects of LY379268 on Fos immunoreactivity within experimentally and ethanol-naive rats were similar to those in animals exposed to stress or the ethanol $\mathrm{S}^{+}$and treated with the $\mathrm{mGlu}_{2 / 3}$ agonist. Specifically, no differences in Fos immunoreactivity were observed within the mPFC, NAC, VTA, and BLA of LY379268treated versus VEH-treated rats $(3 \mathrm{mg} / \mathrm{kg})($ Fig. $3 A-D)$. Within the CA1 $(U=4 ; p<0.05)$ and DG $(U=2 ; p<0.01)$, LY379268 significantly reduced Fos-positive cells compared with vehicle (Fig. 3E). LY did not alter Fos-positive cell counts in the CA3. Within the CeA-L $(U=0 ; p<0.01)$, CeA-M $(U=5.5 ; p<0.05)$, BST-LD $(U=4 ; p<0.05)$, and mpPVN $(U=1.5 ; p<0.01)$, Fos-positive cell counts were significantly elevated in LY379268over vehicle-treated rats (Fig. $3 F$ ).

\section{Discussion}

Activation of group II mGluRs by a selective $\mathrm{mGlu}_{2 / 3}$ agonist (LY379268) dose dependently blocked the effects of both stressand drug-related environmental stimuli on the recovery of extinguished ethanol-seeking behavior. The $\mathrm{mGlu}_{2 / 3}$ agonist did not interfere with food-maintained responding, consistent with previous work in which LY379268 did not alter behavior reinforced by palatable natural rewards (Baptista et al., 2004; Bossert et al., 2004). Furthermore, at the dose range used here, LY379268 is devoid of motoric side effects (Cartmell et al., 1999, 2000), indicating that the "anti-reinstatement" actions of the drug cannot be attributed to motor impairment or sedation. The behavioral effects of LY379268 therefore confirm that interference with the response-reinstating effects of cocaine- and heroin-related environmental stimuli by LY379268 (Baptista et al., 2004; Bossert et al., 2004) extends to the effects of contextual stimuli conditioned to ethanol, thereby implicating group II mGluR-regulated neural mechanisms in the control of behavior by drug cues regardless of drug class. At the same time, the results provide evidence that the

anxiolytic profile of $\mathrm{mGlu}_{2 / 3}$ agonists emerging in animal and human studies (for review, see Swanson et al., 2005) extends to attenuation of stress-induced ethanol-seeking behavior.

Ethanol $\mathrm{S}^{+}$exposure increased c-fos expression (compared with extinction controls) in cortical and limbic brain regions with an established role in conditioned reinstatement (i.e., the mPFC, NACc, HIPPO, BLA, and VTA), confirming previous reports of increased c-fos expression within these sites by environments or contextual cues associated with drugs of abuse, including ethanol (Topple et al., 1998; Ciccocioppo et al., 1999; Franklin and Druhan, 2000; Neisewander et al., 2000; Schroeder et al., 2003). Additionally, the ethanol $\mathrm{S}^{+}$increased Fos immunoreactivity within the CeA and BST-LD, brain regions that regulate behavioral responses to stress, including stress-induced reinstatement of drugseeking (Shaham et al., 2003). Rats subjected to footshock stress showed strong increases in Fos-positive neurons within the brain stress circuit, including the CeA, mpPVN, and BST-LD, as well as in mesocorticolimbic circuitry components, including the NAC, BLA, and VTA. The lack of significant effects of footshock on hippocampal and mPFC c-fos expression differs from previous reports that acute stress activates both mPFC and HIPPO neurons (Cullinan et al., 1995; Funk et al., 2006). A possible explanation for this discrepancy is that mPFC and HIPPO neurons developed some hyporesponsiveness to stress as a result of the modest but prolonged daily ethanol exposure, as suggested by a previous report showing decreased stress-induced hippocampal and prefrontal cortical c-fos expression after acute ethanol treatment (Ryabinin et al., 1995).

Overall, there was marked overlap in the pattern of neural activation produced by footshock and ethanol cue exposure. However, ethanol cue-exposed rats showed stronger activation of brain regions linked to motivation and reward (i.e., $\mathrm{mPFC}$ and HIPPO) than rats subjected to footshock, whereas footshock produced stronger neural activation within brain stress sites, in particular the mpPVN. Both footshock and the ethanol $\mathrm{S}^{+}$activated the CeA and BST-LD, a finding that may reflect possible stress or anxiety-like effects of the ethanol cue. Such effects would be consistent with the suggestion that frustration associated with the absence of ethanol reward in an ethanol-predictive stimulus environment may trigger an aversive motivational state resulting in stress-like neural activation patterns (Topple et al., 1998). Alternatively, these effects may be related to the possibility that stress and drug cue exposure induce a similar pattern of neural activation, as suggested by recent clinical findings showing that craving states associated with drug cue exposure are accompanied by anxiety and hypothalamic-pituitary-adrenal (HPA) axis activation (Sinha et al., 2003; Fox et al., 2005).

In ethanol-naive rats, LY379268 produced a distinct pattern of neural effects, characterized by increased c-fos expression within the CeA, BST-LD, and mpPVN and decreased c-fos expression in the hippocampus. These effects resemble those produced by LY354740 [(+)-2-aminobicyclo[3.1.0]-hexane-2,6-dicarboxylate monohydrate] (a selective $\mathrm{mGlu}_{2 / 3}$ agonist structurally related to LY379268) in drug-naive rats (Linden et al., 2004), suggesting that the pattern of regionally specific changes in c-fos expression observed here represents a neural effect shared by different $\mathrm{mGlu}_{2 / 3}$ agonists. In rats subjected to reinstatement tests, LY379268 distinctly modified brain c-fos expression induced by footshock and the ethanol cue. These effects, however, remained confined to the same brain regions as in ethanol-naive rats. Furthermore, the direction of changes in neural activation remained consistent with that in ethanol-naive rats. Thus, neither repeated ethanol exposure during the training phase nor 
A

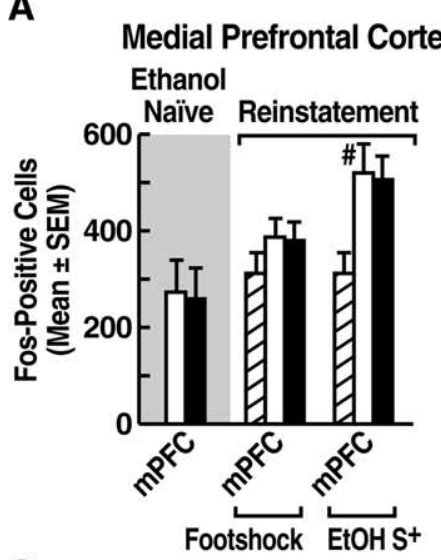

C

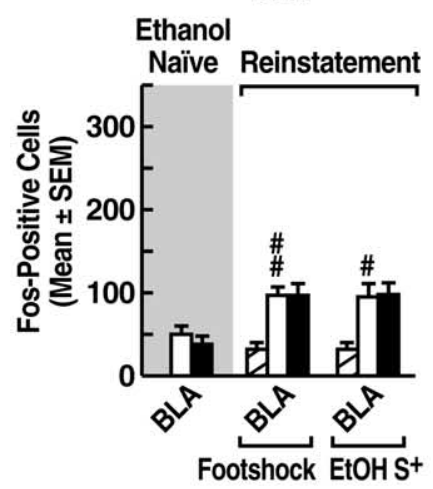

B

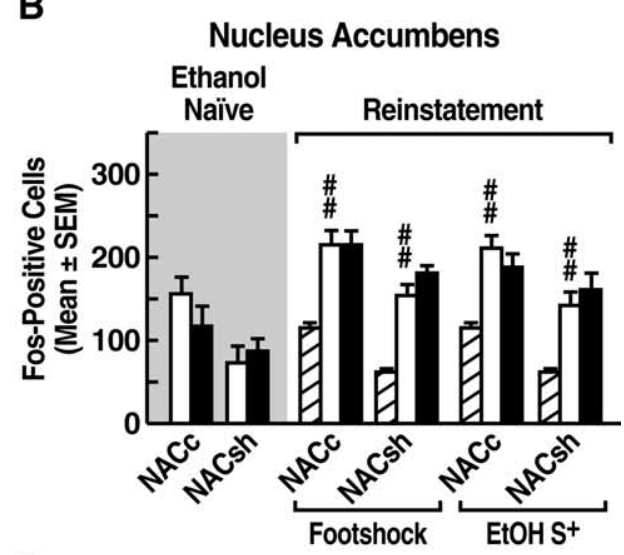

D

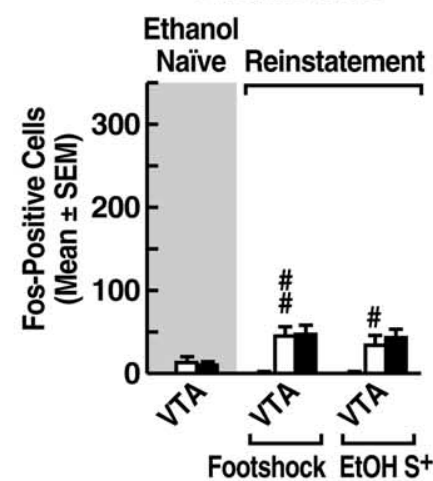

$\mathbf{E}$

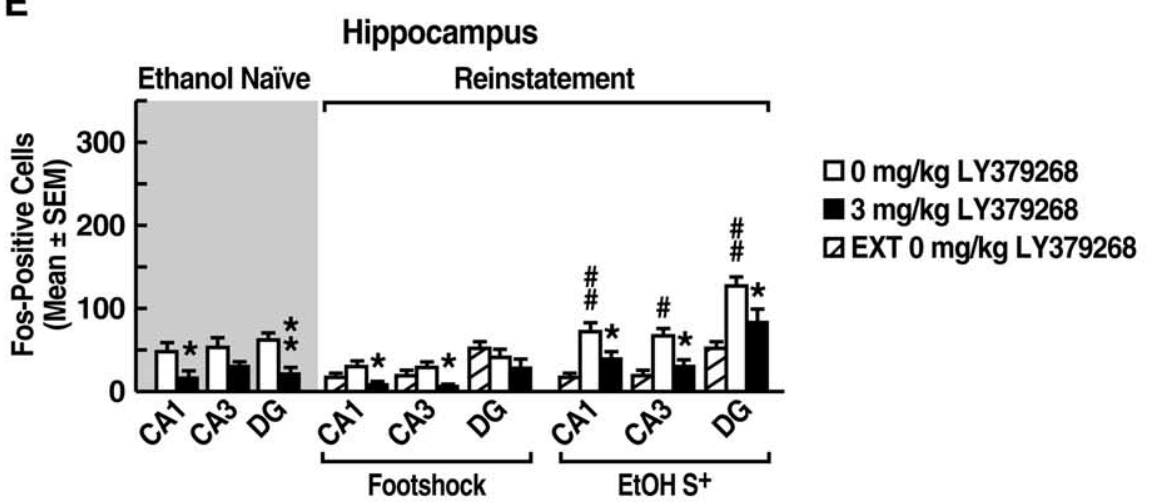

$\mathbf{F}$

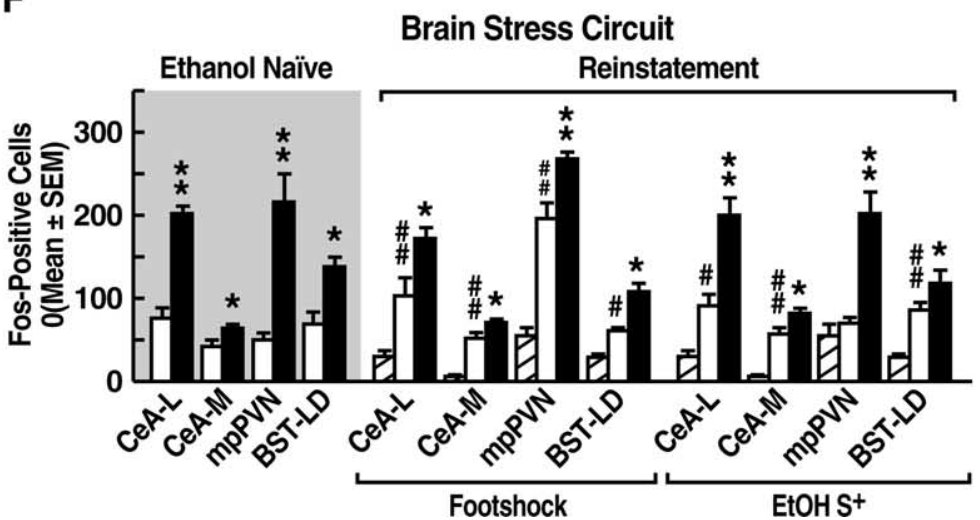

Figure 3. Effects of VEH or LY379268 (3 mg/kg) on Fos immunoreactivity in the mPFC ( $\boldsymbol{A})$, NAC ( $\boldsymbol{B})$, BLA (C), VTA A10 cells $(\boldsymbol{D}), \mathrm{HIPPO}(\boldsymbol{E})$, and stress circuitry $(\boldsymbol{F})$ in ethanol-naive rats and in rats after extinction (EXT) or reinstatement (Footshock, EtOH $S^{+}$) sessions. ${ }^{*} p<0.05,{ }^{* *} p<0.01$, different from $0 \mathrm{mg} / \mathrm{kg} \mathrm{LY379268;}{ }^{\#} p<0.05$, ${ }^{\# \#} p<0.01$, different from extinction. For ease of comparison, extinction control data (EXT) are represented with both the Footshock and EtOH $\mathrm{S}^{+}$ reinstatement data.

acute footshock appeared to alter mGluR function in brain regions that were unresponsive to LY379268 in the ethanol-naive control group.

The predominant neural effect of LY379268 in rats of the ethanol cue reinstatement condition was to decrease c-fos expression in the hippocampus and to increase expression in sites mediating behavioral and physiological responses to stress: the CeA, BST-LD, and mpPVN. Although the c-fos expression data do not establish the mechanism(s) by which LY379268 blocked cue-induced reinstatement, they provide important leads in conjunction with existing knowledge of both the function of the brain regions in which neural activity was altered by LY379268 and the functional role of $\mathrm{mGlu}_{2 / 3}$ receptor activation in these regions. Group II mGluRs are densely expressed in the amygdala and hippocampus (Kenny and Markou, 2004). Activation of these receptors inhibits glutamate release presynaptically and dampens neural excitability postsynaptically (Schoepp, 2001). In the case of the hippocampal effects of LY379268, the significant reduction in c-fos expression is consistent with electrophysiological evidence that this $\mathrm{mGlu}_{2 / 3}$ agonist reduces hippocampal neural excitability (Kilbride et al., 1998; Kew et al., 2002). The dorsal hippocampus has an established role in contextual memory retrieval and the occasion-setting action of contextual stimuli (Holland and Bouton, 1999). Moreover, transient lesion studies directly implicate the dorsal hippocampus in the control of drug-seeking by contextual stimuli (Fuchs et al., 2005). One explanation for the attenuation of cue-induced reinstatement by LY379268, therefore, is that decreased excitation of hippocampal glutamatergic efferents by the $\mathrm{mGlu}_{2 / 3}$ agonist (cf. Swanson et al., 2005) interferes with the processing of drug-related contextual information, reducing its motivational impact. It is also possible that the reversal of conditioned reinstatement by LY379268 is related to the role of the hippocampus in fear and anxiety (Gray, 1982). Microinjection of LY354740 into the dorsal hippocampus produces anxiolytic-like effects in animals (Tatarczynska et al., 2001). Because craving states associated with drug cue exposure in humans are accompanied by anxiety (Sinha et al., 2003; Fox et al., 2005), another mechanism by which LY379268 may have attenuated conditioned reinstatement is by reversing anxiogenic consequences of drug cue exposure at the hippocampal level (as well as via CeAmediated anti-anxiety actions discussed below). 
Consistent with the pattern of neural effects in ethanol-naive rats, LY379268 did not modify c-fos expression induced by the $\mathrm{EtOH} \mathrm{S}^{+}$in the mPFC, VTA, NAC, and BLA. Although group II mGluRs are widely expressed throughout these regions (Kenny and Markou, 2004), this finding suggests that LY379268 does not attenuate conditioned reinstatement through an action in these sites. It cannot be ruled out fully, however, that LY379268 effects in one or more of these brain regions contributed to the reversal of conditioned reinstatement because c-fos is not a universal marker of neural activity. Indeed, LY379268 did not alter $\mathrm{S}^{+}$-induced c-fos expression in the VTA, although intraVTA administration of LY379268 blocked, albeit not dose dependently, contextinduced heroin reinstatement (Bossert et al., 2004). Moreover, it cannot be ruled out that effects in brain regions expressing $\mathrm{mGlu}_{2 / 3}$ receptors such as the ventral pallidum, thalamus, or rhinal cortical areas (Ohishi et al., 1993a,b) with connections to the hippocampus (brain regions that were not examined) may have played some role in the reduction of conditioned reinstatement by LY379268.

In rats subjected to footshock stress, LY379268 produced effects similar to those in ethanol cue-exposed rats, with increased c-fos expression in stress-regulatory sites, including the CeA, BST-LD, and mpPVN, and decreased expression in the CA1 and CA3 regions of the hippocampus. Discrete intra-CeA administration of LY354740 into the CeA attenuates anxiety-like behavior in the fear potentiated startle model (Walker et al., 2002). Anxiolytic actions of $\mathrm{mGlu}_{2 / 3}$ receptor activation in the CeA, therefore, are likely to be directly relevant for the attenuation of stress-induced reinstatement. Based on findings that $\mathrm{mGlu}_{2 / 3}$ receptor activation increases c-fos expression within glutamic acid decarboxylase-positive cells in the CeA-L, it has been suggested that $\mathrm{mGlu}_{2 / 3}$ receptor activation "disinhibits" GABAergic neurons that innervate the CeA by reducing excitatory glutamatergic input onto intervening GABAergic interneurons (Swanson et al., 2005). Whether a similar "disinhibition" of GABAergic interneurons accounts for the increased $c$-fos expression in the BST-LD is presently unclear. Moreover, it remains to be determined by what mechanism $\mathrm{mGlu}_{2 / 3}$ agonist-induced c-fos expression in the CeA (and BST-LD) is linked to anxiolytic action, because both anxiogenic and anxiolytic agents increase immediate early gene expression within these nuclei (Thompson and Rosen, 2006).

In light of the reduction in hippocampal neural activity by LY379268, hippocampal-mediated anti-anxiety actions may also have contributed to the attenuation of stress-induced reinstatement. Because footshock, by itself, did not produce significant elevations in hippocampal Fos immunoreactivity over that in extinction controls, a role of the hippocampus in stress-induced reinstatement could not be confirmed. Nonetheless, it remains possible that $\mathrm{mGlu}_{2 / 3}$ activation indirectly dampened the effects of footshock at "downstream" neural targets by reducing tonic excitatory glutamatergic output from the hippocampus. Additionally, it cannot be ruled out that direct or indirect effects of LY379268 on neural substrates implicated in stress-induced re-
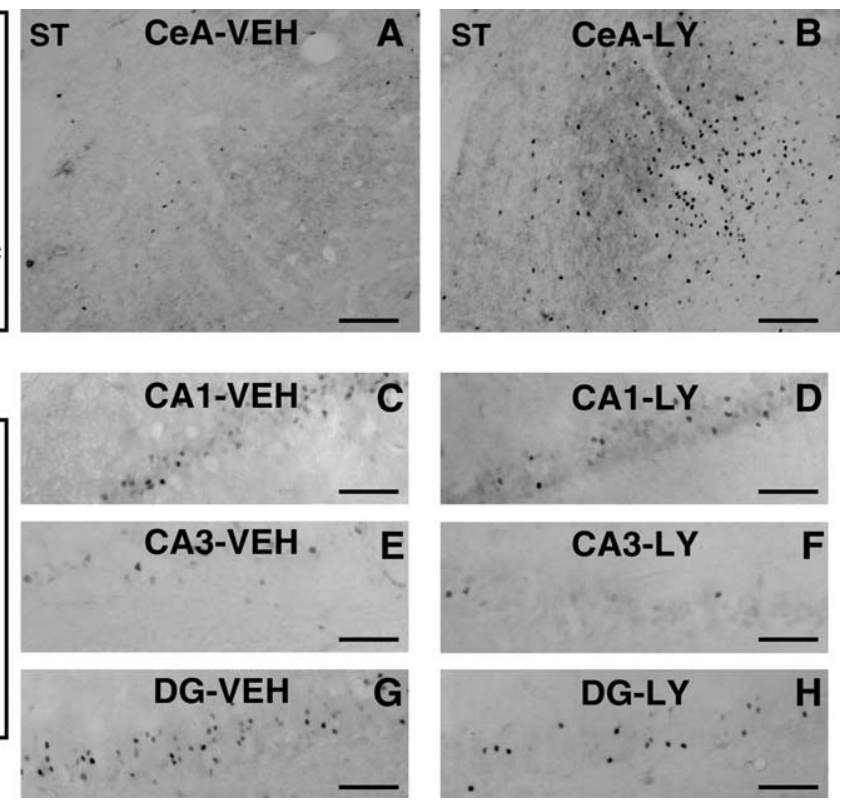

Figure 4. Photomicrographs and schematic drawings depicting the area of analysis and illustrating typical changes in Fos immunoreactivity within the CeA and hippocampus of an animal treated with either VEH or LY379268 (3 mg/kg). Because (Y) 378 produced similar changes in Fos immunoreactivity in both the conditioned and stress-induced reinstatement tests (see

instatement, but not examined in the present study, such as the lateral tegmental nuclei (Shaham et al., 2003), ventral pallidum (McFarland et al., 2004), and lateral hypothalamus (Boutrel et al., 2005) contributed in some manner to the "anti-reinstatement" actions of the mGlu2/3 agonist.

Last, in both the footshock and the ethanol $\mathrm{S}^{+}$condition, LY379268 increased c-fos expression within the mpPVN, an effect known to be positively correlated with activation of the HPA axis (Buller et al., 1998). Despite this stress-like effect, both cueand stress-exposed animals showed decreased reinstatement. The activation of mpPVN neurons is perhaps most parsimoniously explained in terms of nonspecific disinhibition of local hypothalamic circuits by LY379268, similar to the effects of other anxiolytic agents that acutely increase c-fos expression in the mpPVN (Salminen et al., 1996).

It is of interest to note that, in a recent report, only a high, locomotor suppressant $5 \mathrm{mg} / \mathrm{kg}$ dose of LY379268 was effective in reversing reinstatement induced by ethanol cue exposure paired with noncontingent administration of an ethanol "priming" dose to enhance ethanol-seeking behavior (Backstrom and Hyytia, 2005). The failure to observe suppression of locomotor activity in this study at doses smaller than $5 \mathrm{mg} / \mathrm{kg}$ strengthens the conclusion that the effects of LY379268 observed here are not related to nonspecific impairments of motor behavior. With respect to the high LY379268 dose necessary to reverse reinstatement (a finding that contrasts with the present results), it is necessary to keep in mind that ethanol-seeking in this report must be presumed to have been driven primarily by the ethanol priming dose rather than representing conditioned reinstatement. The weak interference by LY379268 with ethanol-directed behavior under these conditions is consistent with evidence that, compared with its effects on cue-induced reinstatement, this $\mathrm{mGlu}_{2 / 3}$ agonist is considerably less effective in attenuating the acute reinforcing effects of ethanol (Zhao et al., 2005), cocaine (Baptista et al., 2005), and heroin (Bossert et al., 2004, 2005). 
In summary, the results implicate group II mGluRs as a common neuropharmacological substrate for ethanol-seeking elicited by both drug cues and stress and point toward the hippocampus and stress-regulatory sites within the extended amygdala as neurocircuitry components through which group II mGluR activation exerts these effects. In view of previous findings that LY379268 attenuates the response-reinstating effects of cocaine and heroin-related environmental stimuli (Baptista et al., 2004; Bossert et al., 2004), the data suggest that $\mathrm{mGlu}_{2 / 3}$ receptors participate in mediating the effects of contextual stimuli conditioned to drugs of abuse with widely different mechanisms of action. Moreover, based on the current understanding of the neurocircuitry mediating addiction-relevant effects of stress (Shaham et al., 2003), a role of group II mGluRs in stress-induced reinstatement is likely to also hold across different drugs of abuse. Because stress and craving evoked by drug-related environmental stimuli are major risk factors for relapse to drug use, these results identify group II mGluRs as promising targets for relapse prevention.

\section{References}

Backstrom P, Hyytia P (2005) Suppression of alcohol self-administration and cue-induced reinstatement of alcohol seeking by the mGlu2/3 receptor agonist LY379268 and the mGlu8 receptor agonist (S)-3,4-DCPG. Eur J Pharmacol 528:110-118.

Baptista MA, Martin-Fardon R, Weiss F (2004) Preferential effects of the metabotropic glutamate $2 / 3$ receptor agonist LY379268 on conditioned reinstatement versus primary reinforcement: comparison between cocaine and a potent conventional reinforcer. J Neurosci 24:4723-4727.

Baptista MAS, Martin-Fardon R, Weiss F (2005) Effect of LY379268, an mGlu2/3 agonist, on cocaine self-administration and cocaine primeinduced cocaine seeking behavior in cocaine-escalated versus nonescalated rats. Soc Neurosci Abstr 31:561.3.

Bossert JM, Liu SY, Lu L, Shaham Y (2004) A role of ventral tegmental area glutamate in contextual cue-induced relapse to heroin seeking. J Neurosci 24:10726-10730.

Bossert JM, Busch RF, Gray SM (2005) The novel mGluR2/3 agonist LY379268 attenuates cue-induced reinstatement of heroin seeking. NeuroReport 16:1013-1016.

Boutrel B, Kenny PJ, Specio SE, Martin-Fardon R, Markou A, Koob GF, de Lecea L (2005) Role for hypocretin in mediating stress-induced reinstatement of cocaine-seeking behavior. Proc Natl Acad Sci USA 102:19168-19173.

Buller KM, Xu Y, Day TA (1998) Indomethacin attenuates oxytocin and hypothalamic-pituitary-adrenal axis responses to systemic interleukin1 $\beta$. J Neuroendocrinol 10:519-528.

Cartmell J, Monn JA, Schoepp DD (1999) The metabotropic glutamate 2/3 receptor agonists LY354740 and LY379268 selectively attenuate phencyclidine versus $d$-amphetamine motor behaviors in rats. J Pharmacol Exp Ther 291:161-170.

Cartmell J, Monn JA, Schoepp DD (2000) Attenuation of specific PCPevoked behaviors by the potent mGlu2/3 receptor agonist, LY379268 and comparison with the atypical antipsychotic, clozapine. Psychopharmacology (Berl) 148:423-429.

Ciccocioppo R, Angeletti S, Chhada M, Perfumi M, Froldi R, Massi M (1999) Conditioned taste aversion induced by ethanol in alcohol-preferring rats: influence of the method of ethanol administration. Pharmacol Biochem Behav 64:563-566.

Cullinan WE, Herman JP, Battaglia DF, Akil H, Watson SJ (1995) Pattern and time course of immediate early gene expression in rat brain following acute stress. Neuroscience 64:477-505.

Dayas CV, Buller KM, Day TA (1999) Neuroendocrine responses to an emotional stressor: evidence for involvement of the medial but not the central amygdala. Eur J Neurosci 11:2312-2322.
Fox HC, Talih M, Malison R, Anderson GM, Kreek MJ, Sinha R (2005) Frequency of recent cocaine and alcohol use affects drug craving and associated responses to stress and drug-related cues. Psychoneuroendocrinology 30:880-891.

Franklin TR, Druhan JP (2000) Expression of Fos-related antigens in the nucleus accumbens and associated regions following exposure to a cocaine-paired environment. Eur J Neurosci 12:2097-2106.

Fuchs RA, Evans KA, Ledford CC, Parker MP, Case JM, Mehta RH, See RE (2005) The role of the dorsomedial prefrontal cortex, basolateral amygdala, and dorsal hippocampus in contextual reinstatement of cocaine seeking in rats. Neuropsychopharmacology 30:296-309.

Funk D, Li Z, Le AD (2006) Effects of environmental and pharmacological stressors on c-fos and corticotropin-releasing factor mRNA in rat brain: Relationship to the reinstatement of alcohol seeking. Neuroscience 138:235-243.

Gray J (1982) Precis of the neuropsychology of anxiety: an enquiry into the functions of the septo-hippocampal system. Behav Brain Sci 5:469-534.

Holland PC, Bouton ME (1999) Hippocampus and context in classical conditioning. Curr Opin Neurobiol 9:195-202.

Kenny PJ, Markou A (2004) The ups and downs of addiction: role of metabotropic glutamate receptors. Trends Pharmacol Sci 25:265-272.

Kew JN, Pflimlin MC, Kemp JA, Mutel V (2002) Differential regulation of synaptic transmission by mGlu2 and mGlu3 at the perforant path inputs to the dentate gyrus and CA1 revealed in mGlu2-/- mice. Neuropharmacology 43:215-221.

Kilbride J, Huang LQ, Rowan MJ, Anwyl R (1998) Presynaptic inhibitory action of the group II metabotropic glutamate receptor agonists, LY354740 and DCG-IV. Eur J Pharmacol 356:149-157.

Linden AM, Greene SJ, Bergeron M, Schoepp DD (2004) Anxiolytic activity of the MGLU2/3 receptor agonist LY354740 on the elevated plus maze is associated with the suppression of stress-induced c-Fos in the hippocampus and increases in c-Fos induction in several other stress-sensitive brain regions. Neuropsychopharmacology 29:502-513.

McFarland K, Davidge SB, Lapish CC, Kalivas PW (2004) Limbic and motor circuitry underlying footshock-induced reinstatement of cocaine-seeking behavior. J Neurosci 24:1551-1560.

Neisewander JL, Baker DA, Fuchs RA, Tran-Nguyen LT, Palmer A, Marshall JF (2000) Fos protein expression and cocaine-seeking behavior in rats after exposure to a cocaine self-administration environment. J Neurosci 20:798-805.

O'Brien CP, Childress AR, Ehrman R, Robbins SJ (1998) Conditioning factors in drug abuse: can they explain compulsion? J Psychopharmacol $12: 15-22$

Ohishi H, Shigemoto R, Nakanishi S, Mizuno N (1993a) Distribution of the messenger RNA for a metabotropic glutamate receptor, mGluR2, in the central nervous system of the rat. Neuroscience 53:1009-1018.

Ohishi H, Shigemoto R, Nakanishi S, Mizuno N (1993b) Distribution of the mRNA for a metabotropic glutamate receptor (mGluR3) in the rat brain: an in situ hybridization study. J Comp Neurol 335:252-266.

Ryabinin AE, Melia KR, Cole M, Bloom FE, Wilson MC (1995) Alcohol selectively attenuates stress-induced c-fos expression in rat hippocampus. J Neurosci 15:721-730.

Salminen O, Lahtinen S, Ahtee L (1996) Expression of Fos protein in various rat brain areas following acute nicotine and diazepam. Pharmacol Biochem Behav 54:241-248.

Schoepp DD (2001) Unveiling the functions of presynaptic metabotropic glutamate receptors in the central nervous system. J Pharmacol Exp Ther 299:12-20.

Schroeder BE, Schiltz CA, Kelley AE (2003) Neural activation profile elicited by cues associated with the anxiogenic drug yohimbine differs from that observed for reward-paired cues. Neuropsychopharmacology 28:14-21.

See RE (2002) Neural substrates of conditioned-cued relapse to drugseeking behavior. Pharmacol Biochem Behav 71:517-529.

Shaham Y, Shalev U, Lu L, De Wit H, Stewart J (2003) The reinstatement model of drug relapse: history, methodology and major findings. Psychopharmacology (Berl) 168:3-20.

Sinha R, Fuse T, Aubin LR, O’Malley SS (2000) Psychological stress, drugrelated cues and cocaine craving. Psychopharmacology (Berl) 152: 140-148. 
Sinha R, Talih M, Malison R, Cooney N, Anderson GM, Kreek MJ (2003) Hypothalamic-pituitary-adrenal axis and sympatho-adreno-medullary responses during stress-induced and drug cue-induced cocaine craving states. Psychopharmacology (Berl) 170:62-72.

Swanson CJ, Bures M, Johnson MP, Linden AM, Monn JA, Schoepp DD (2005) Metabotropic glutamate receptors as novel targets for anxiety and stress disorders. Nat Rev Drug Discov 4:131-144.

Tatarczynska E, Klodzinska A, Kroczka B, Chojnacka-Wojcik E, Pilc A (2001) The antianxiety-like effects of antagonists of group I and agonists of group II and III metabotropic glutamate receptors after intrahippocampal administration. Psychopharmacology (Berl) 158: 94-99.

Thompson BL, Rosen JB (2006) Immediate-early gene expression in the central nucleus of the amygdala is not specific for anxiolytic or anxiogenic drugs. Neuropharmacology 50:57-68.

Topple AN, Hunt GE, McGregor IS (1998) Possible neural substrates of beer-craving in rats. Neurosci Lett 252:99-102.

Walker DL, Rattiner LM, Davis M (2002) Group II metabotropic glutamate receptors within the amygdala regulate fear as assessed with potentiated startle in rats. Behav Neurosci 116:1075-1083.

Weiss F (2005) Neurobiology of craving, conditioned reward and relapse. Curr Opin Pharmacol 5:9-19.

Zhao Y, Dayas CV, Weiss F (2005) Effects of the metabotropic glutamate 2/3 agonist LY379268 on reinstatement of ethanol-seeking induced by alcohol-associated environmental stimuli and foot-shock stress. Alcohol Clin Exp Res Suppl 29:58A. 